\title{
Design and Analysis of Fused Deposition Modeling 3D Printer Nozzle for Color Mixing
}

\author{
Shanling Han, ${ }^{1}$ Yu Xiao, ${ }^{1}$ Tao Qi, ${ }^{1}$ Zhiyong Li, ${ }^{1}$ and Qingliang Zeng ${ }^{2}$ \\ ${ }^{1}$ College of Transportation, Shandong University of Science and Technology, Qingdao 266590, China \\ ${ }^{2}$ College of Mechanical and Electronic Engineering, Shandong University of Science and Technology, Qingdao 266590, China \\ Correspondence should be addressed to Qingliang Zeng; qlzeng@163.com
}

Received 24 May 2017; Revised 22 June 2017; Accepted 2 July 2017; Published 13 August 2017

Academic Editor: Gianluca Percoco

Copyright (c) 2017 Shanling Han et al. This is an open access article distributed under the Creative Commons Attribution License, which permits unrestricted use, distribution, and reproduction in any medium, provided the original work is properly cited.

\begin{abstract}
Fused deposition modeling (FDM) has been one of the most widely used rapid prototyping (RP) technologies leading to the increase in market attention. Obviously it is desirable to print 3D objects; however, existing FDM printers are restricted to printing only monochrome objects because of the entry-level nozzle structure, and literature on the topic is also sparse. In this paper, the CAD model of the nozzle is established first by UG (Unigraphics NX) software to show the structure of fused deposition modeling 3D printer nozzle for color mixing. Second, the flow channel model of the nozzle is extracted and simplified. Then, the CAD and finite element model are established by UG and ICEM CFD software, respectively, to prepare for the simulation. The flow field is simulated by Fluent software. The nozzle's suitable temperature at different extrusion speeds is obtained, and the reason for the blockage at the intersection of the heating block is revealed. Finally, test verification of the nozzle is performed, which can produce mixed-color artifacts stably.
\end{abstract}

\section{Introduction}

3D printing technology's areas include advanced materials manufacturing, software engineering, and control technology. This is a work of making three-dimensional solid objects from digital files [1-5]. Therefore, an increasing number of people consider that the future of 3D printing will usher in the next industrial revolution [6-10]. Most printing nozzle devices are currently based on 3D desktop FDM printers that can print using only monochrome filaments, which restrict the application of 3D printers [11-13]. So it is necessary to carry out research of color mixing printing.

Reiner et al. [14] detailed a method that produces continuous tone imagery by using the two color heads of entry-level fused deposition modeling 3D printers. Arikan et al. [15] described a whole color-managed 3D printing workflow and paid attention to the measurement of colors of highly translucent printing materials later. Khalil et al. [16], from Drexel University independently developed a multinozzle biopolymer deposition system that consisted of four micronozzles: pneumatic microvalve, piezoelectric nozzle, solenoid valve, and precision extrusion deposition nozzle. Each nozzle system can work separately or simultaneously as required.

In this paper, the design of a $3 \mathrm{D}$ printer nozzle for color mixing is completed by UG software where the flow channel model of the entire device is extracted and simplified. Optimal filament feed speed at different temperatures is studied through computer simulations which is supported by experiment later. The study of the distribution of the pressure field and the velocity field at the nozzle hole and the intersection is built on the combination of the temperature field and filament feed speed. The shortcomings of the device are analyzed and summarized.

\section{Design of FDM 3D Printer Nozzle for Color Mixing}

2.1. Establishment of the Heating Block Model. The heating block of a $3 \mathrm{D}$ printer nozzle device is usually set through throat pipe in the fixed block which is driven by a motor in 


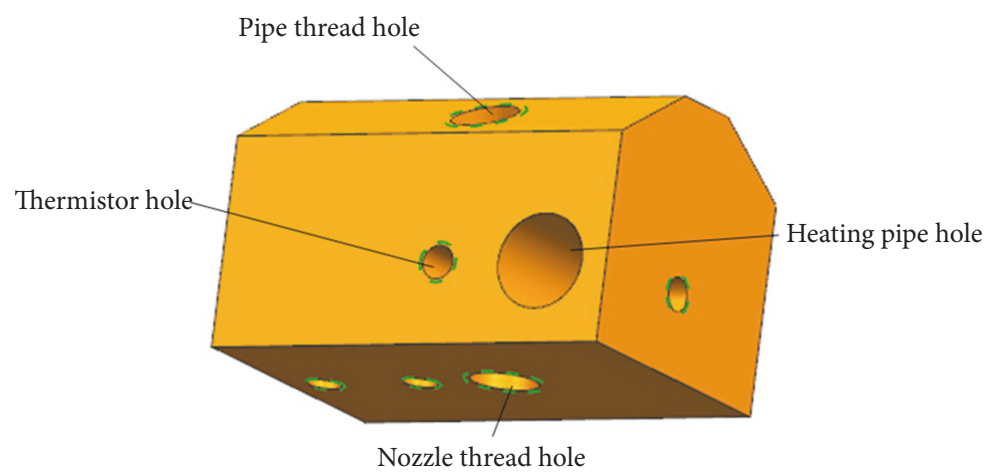

FIGURE 1: Model of the heating block.

the guide rail to realize the function of continuous print [1719]. In order to ensure the mixing of filaments in the heating block, a larger heating block cavity is needed to meet the actual requirements. As a consequence, the size of the existing heating block is increased to ensure the smooth input of two kinds of filaments. In addition, the face of the throat threaded hole is designed to be at an angle of $30^{\circ}$ to the horizontal position, which is not only conducive to the handling of the pipe, but also conducive to the heat dissipation of throat pipe. This design results in the loss of the function of the throat pipe connecting with the fixed block and the heating block. As a consequence, two threaded holes are arranged on one side of the heating block to connect the fixed block using a hex socket screw. The length of the heating block is $32 \mathrm{~mm}$, the width of the bottom and the top is $22 \mathrm{~mm}$ and $6.5 \mathrm{~mm}$, respectively, and the height is $20 \mathrm{~mm}$. The heating block is as shown in Figure 1.

2.2. Establishment of the Whole Model. The nozzle device of the $3 \mathrm{D}$ printer is mainly composed of a fixed block, heating block, throat pipes, and nozzle [20-23]. The heating block consists of a throat pipe thread hole, nozzle thread hole, heating pipe hole, and thermistor hole. The nozzle, throat pipe, and thermistor are attached to a heating block using screw threads. The heating pipe is arranged in the heating pipe hole directly. The heating pipe is fastened into the threaded hole using screws. However, the throat pipe will be out of the function of connecting with the fixed block and the heating block after the completion of device design. As a consequence, two screw holes are set where the fixed block and the heating block occur. The heating block is installed into the fixed block by using a hex socket screw. The assembling simulation of the $3 \mathrm{D}$ printer nozzle model is done by UG software. The throat is installed into the pipe thread hole of the heating block; meanwhile, the nozzle is fastened into the nozzle thread hole of the heating block. It can be seen from Figure 2 that the heating block and thermistors are omitted. The assembly structure of the whole model is shown in Figure 2. Mixing. Finite element analysis is a numerical method that

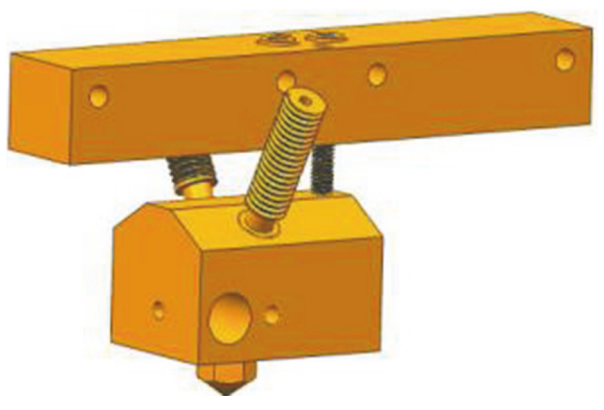

FIGURE 2: Assembly structure of the entire model.

offers a means to find the approximate solution. The finite element analysis of structures requires the use of accurate and reliable finite element models, of equal importance, and the use of efficient finite element method and accurate calculating time. It is misunderstood that the more complex the models are, the more accurate the result will be. So the simplification of the model plays an important role in the finite element analysis. Reasonable simplification of the model can not only improve the efficiency of simulation and shorten the calculation time but also improve the accuracy of the calculation. Simplification mainly focuses on the processing of the models of the heating block, nozzle, and throat pipe. Therefore, the fixed block, hex socket screw, and other components are removed. The simplified heating block model, the simplified nozzle model, and the simplified throat pipe model are shown in Figure 3.

\section{Flow Field Simulation Analysis of ABS Material in Printer Nozzle for Color Mixing}

3.1. Establishment of the Flow Channel Model. In the previous chapter, the model of the 3D printer nozzle for color mixing has been simplified. The flow channel model of the entire mixing device, established by using UG software, is currently extracted and simplified. The parameters of a simplified flow channel model are presented in Table 1 . The model which will be imported into ICEM CFD meshing software is established by UG. In order to improve the quality of mesh, a Tetra/Mixed 


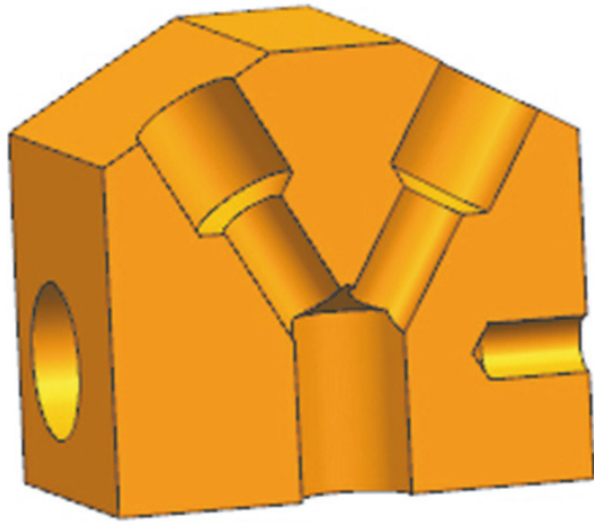

(a)

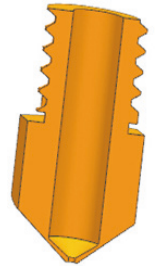

(b)

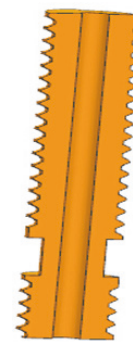

(c)

Figure 3: Simplified model of (a) heating block, (b) nozzle, and (c) throat pipe.

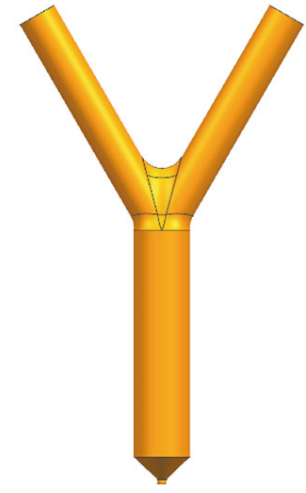

(a)

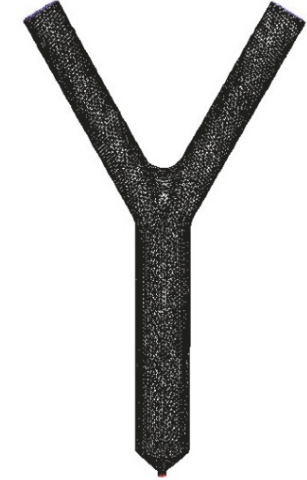

(b)

FIGURE 4: (a) 3D model and (b) finite element model of the flow channel.

TABLE 1: Size of the simplified flow channel.

\begin{tabular}{lc}
\hline Item & Quantity \\
\hline Branch pipe length $(\mathrm{mm})$ & 10 \\
Main pipe length $(\mathrm{mm})$ & 11 \\
Branch pipe angle $\left(^{\circ}\right)$ & $60^{\circ}$ \\
Branch pipe diameter $(\mathrm{mm})$ & 1.75 \\
Main pipe diameter $(\mathrm{mm})$ & 2 \\
Outlet diameter $(\mathrm{mm})$ & 0.4 \\
\hline
\end{tabular}

meshing type (which is mainly composed of tetrahedral mesh elements) is chosen to mesh the model. As a result, 4936 nodes and 27442 elements are generated. The first entrance, the second entrance, export, and wall are all defined in ICEM CFD software. The finite element model is imported into the Fluent software to carry out fluid analysis. Flow channel model and finite element model of the flow channel are shown in Figure 4.
3.2. Material Properties of ABS Material and Setting of Model Boundary Conditions. ABS material is one of the most widely used polymers in the world, touching virtually every part of our lives [24]. ABS materials are an excellent choice for models, prototypes, patterns, tools, and end-use parts. Much stronger than the FDM materials just a few years ago, ABS for FDM machines offers greater tensile, impact, and flexural strength today [25]. The ABS material existing in the flow channel is selected as the research object; meanwhile the situation of ABS mixing in the molten state is studied. Thus, the optimum combination of the different filament feed speed and the corresponding heating temperature is summarized. Properties of ABS material are shown in Table 2.

The boundary conditions are set based on the simplified flow channel model. The boundary conditions are shown in Figure 5. Both the first inlet and second inlet are set to the speed boundary. The material is ABS filament at a diameter of $1.75 \mathrm{~mm}$. The initial temperature of ABS filament is set to $25^{\circ} \mathrm{C}$; at the same time, the outlet is set to flow boundary. 
TABLE 2: Properties of ABS material.

\begin{tabular}{lc}
\hline Item & Quantity \\
\hline Density $\left(\mathrm{kg} / \mathrm{m}^{3}\right)$ & 1020 \\
Elastic modulus $(\mathrm{GPa})$ & 2 \\
Poisson ratio & 0.394 \\
Specific heat capacity $(\mathrm{J} /(\mathrm{kg} \cdot \mathrm{K}))$ & 1386 \\
Thermal conductivity $(\mathrm{W} /(\mathrm{m} \cdot \mathrm{K}))$ & 0.2256 \\
Viscosity $(\mathrm{Pa} \cdot \mathrm{s})$ & 84 \\
\hline
\end{tabular}

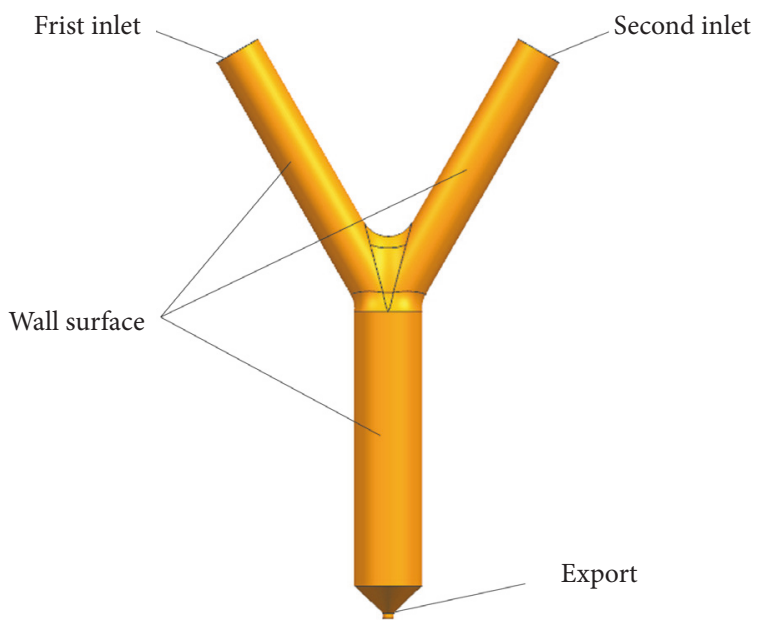

FIGURE 5: Boundary conditions of the flow channel model.

\subsection{Result Analysis}

3.3.1. Simulation Theory Analysis. Printing molten ABS is complex due to high process temperature; in particular, there exists the phenomenon that two filaments mixing in a color mixing nozzle make the distribution of flow field more complex. It is significant that filament material melted completely and mixed at the intersection, in order to realize the function of color mixing print. The driving force will lose due to an abnormal process temperature, which even will be a cause of the failure in the extrusion of molten filament. That is why filament should not be overheated.

The effect of color mixing print depends on whether filament material can be completely melted and mixed at the intersection. The temperature field of two filaments at the intersection is simulated and analyzed through changing the filament feed speed. The optimal combination of filament feed speed and temperature field of the flow channel is obtained by comparing the analysis results.

3.3.2. Simulation Analysis of Two Inlets at a Velocity of $0.2 \mathrm{~mm} / \mathrm{s}$. The meshed finite element model is imported into the Fluent software. The filament feed speeds of the first inlet and the second inlet are both set to a velocity of $0.2 \mathrm{~mm} / \mathrm{s}$; meanwhile, the initial temperature is set to $298.15 \mathrm{~K}$. There is a close contact between the heating block and the wall surface whose temperature is set to $493.15 \mathrm{~K}$. The simulation time is set to $60 \mathrm{~s}$ to help the ABS filament material existing in the flow channel to be observed better; meanwhile the time nodes of $5 \mathrm{~s}, 30 \mathrm{~s}, 50 \mathrm{~s}$, and $60 \mathrm{~s}$ are selected to represent the changes of ABS filament in the flow channel. The temperature distribution in the flow channel is obtained by using simulation, and the temperature contours at different time steps are shown in Figure 6.

It can be seen from the temperature contours that the temperature of the flow channel is relatively low at the time of $5 \mathrm{~s}$. In addition, the temperature will increase gradually as time goes on. Heat is constantly being absorbed by filaments, which leads to a decrease in the temperature of the wall surface. As a consequence, a larger temperature gradient appears in the pipe. As a consequence, the temperature inside the flow channel at a time of $50 \mathrm{~s}$ is considered as the steady state when the amount of ABS material entry into the pipe is $10 \mathrm{~mm}$. The cross section of pipe at the intersection is chosen to make the temperature contours, which is shown in Figure 7.

As can be seen from Figure 7, the temperature of the wall surface is high; on the contrary, the internal temperature of the filament is low. The lowest temperature occurs at the center of the filament, which is about $484.8 \mathrm{~K}$ equal to $211.6^{\circ} \mathrm{C}$. This temperature does not reach the test temperature for smooth extrusion of the filament, which will result in an incomplete melt of filament. In the case where the filament cannot be melted completely, not only can the mixing effect of material be influenced, but also the extrusion will be blocked. Once the blockage occurs at the intersection, the filament cannot be input or output effectively, which will directly lead to the failure of color mixing printing.

In order to melt the ABS filament material at the intersection, the boundary temperature rises to $503.15 \mathrm{~K}$ without any changes in other boundary conditions. The steady state temperature distribution of the flow channel at the time of $50 \mathrm{~s}$ is as shown in Figure 8(a); the temperature distribution of the cross section of intersection is as shown in Figure 8(b).

It can be seen from Figure 8(a) that the steady state temperature distribution is similar to the temperature distribution of the boundary at a temperature of $493.15 \mathrm{~K}$. It can be summed up that the temperature of the flow channel tends to be steady gradually within $50 \mathrm{~s}$. As can be seen from Figure 9, the temperature distribution of intersection is not uniform; meanwhile, the temperature of the center of filament is the lowest, which is about $494 \mathrm{~K}$ equal to $221^{\circ} \mathrm{C}$. The filament can be successfully extruded at this temperature.

Summaries can be made by using simulation. It is appropriate that the temperature of the heating block of the color mixing device is maintained around $503.15 \mathrm{~K}$ when the velocity of the inlet is $0.2 \mathrm{~mm} / \mathrm{s}$.

3.3.3. Simulation Analysis of Two Inlets at a Velocity of $0.5 \mathrm{~mm} / \mathrm{s}$. The boundary conditions are changed during the simulation. The filament feed speed of both inlets is set to $0.5 \mathrm{~mm} / \mathrm{s}$ with the initial temperature set to $298.15 \mathrm{~K}$. There is a close contact between the heating block and the wall surface whose temperature is set to $503.15 \mathrm{~K}$. The process of the filament material reaching the intersection through the 


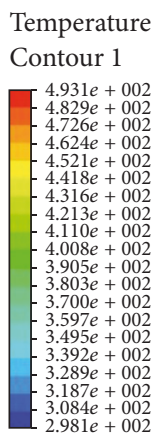

(K)

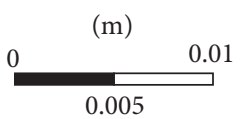

(a)

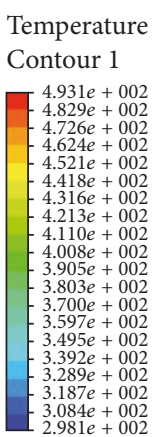

(K)
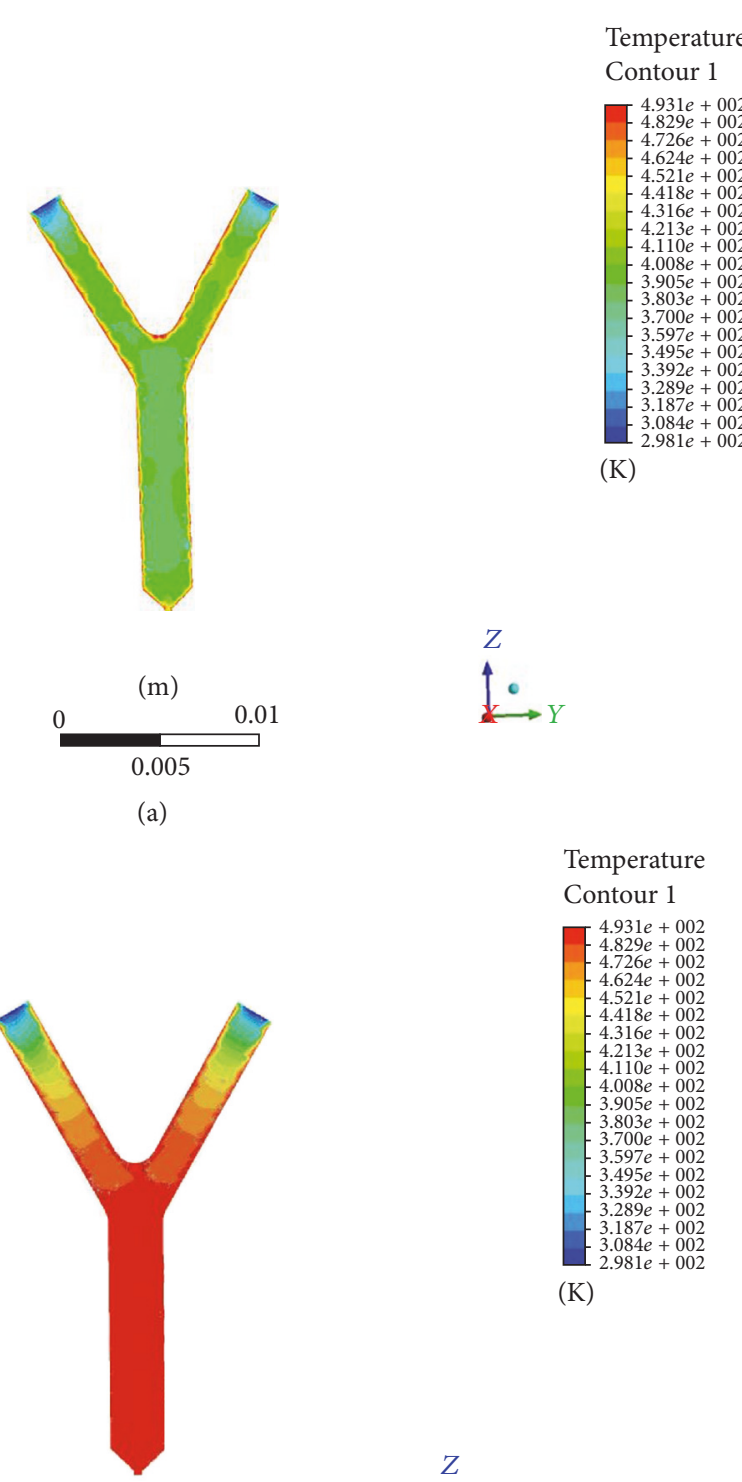

(m)

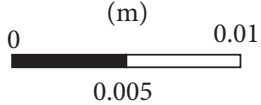

(c)

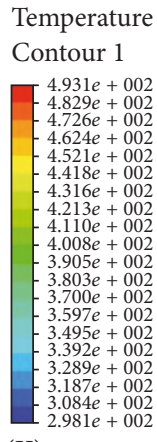

(K)

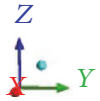

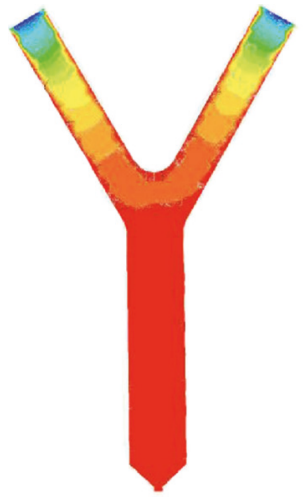
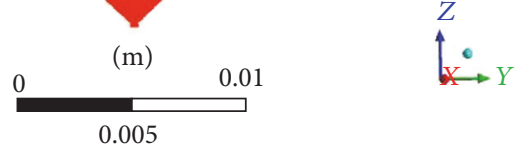

(b)
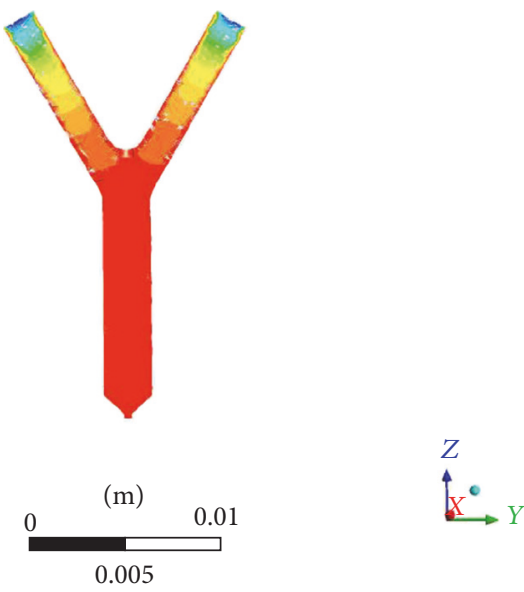

(d)

Figure 6: Temperature contours of the flow channel at the temperature of $493.15 \mathrm{~K}$ : (a) at the time of $5 \mathrm{~s}$; (b) at the time of $30 \mathrm{~s}$; (c) at the time of $50 \mathrm{~s}$; (d) at the time of $60 \mathrm{~s}$.

branch pipe takes approximately $20 \mathrm{~s}$. The simulation time is set to $60 \mathrm{~s}$, in order to allow the temperature distribution of ABS filament at the intersection to be observed better and represent the changes in the temperature of ABS filament existing in flow channel at the time of $20 \mathrm{~s}$. The temperature changes are shown in Figure 9(a). The intersection position is chosen to make the temperature contours which are shown in Figure 9(b).

As can be seen from Figure 9(a), at the time of $20 \mathrm{~s}$, filament gathers at the intersection, and the temperature of the filament is evidently lower than that of the flow channel. The temperature of the cross section shown in Figure 11 is in zonal distribution. The lowest temperature that is $489 \mathrm{~K}$ equal to approximately $216^{\circ} \mathrm{C}$ occurs in the center of filament material, which can meet the requirements for a smooth extrusion of the filament material. The temperature reaches a steady state after $50 \mathrm{~s}$. The temperature of filament at the intersection will rise again, but it is still in a reasonable range for ABS filament melting.

Summaries can be made by using the simulation when the velocity of two inlets is at $0.5 \mathrm{~mm} / \mathrm{s}$. The heating temperature should be maintained at around $503.15 \mathrm{~K}$, which can meet the requirements for $\mathrm{ABS}$ filament melting and mixing at the intersection. 


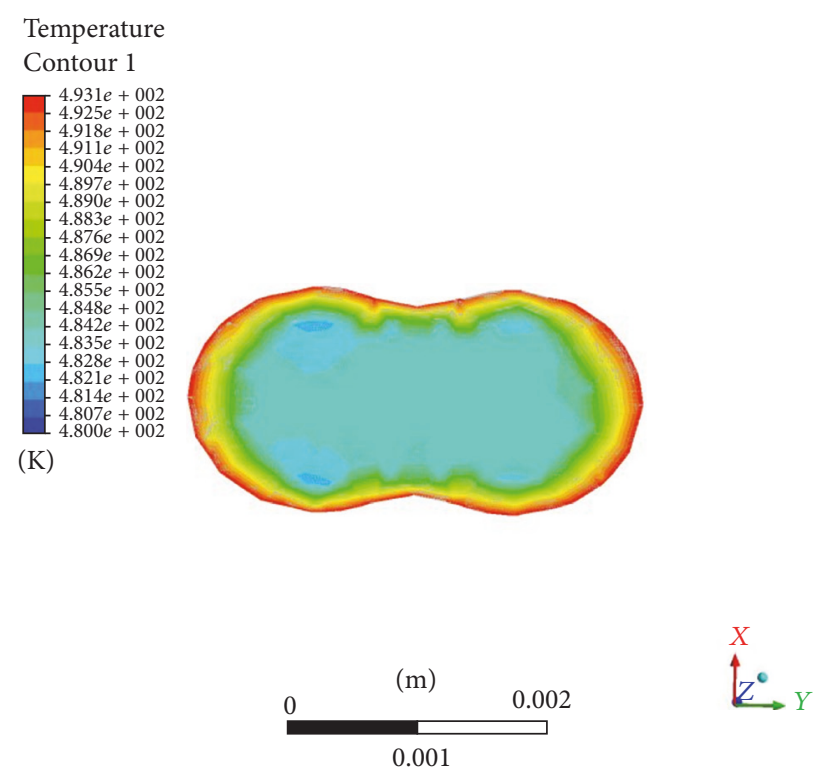

FIGURE 7: Temperature contours of the intersection cross section in the steady state at the temperature of $493.15 \mathrm{~K}$.

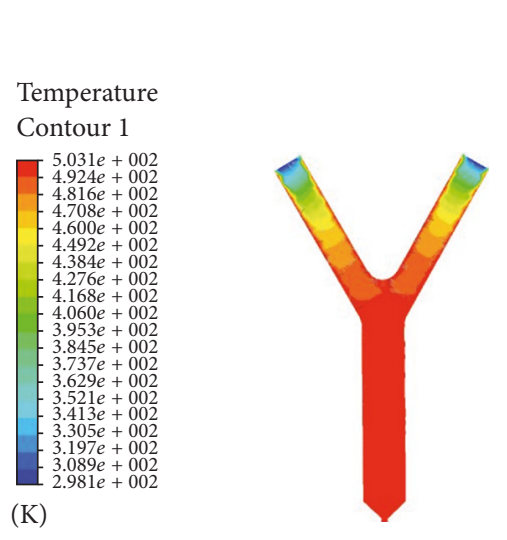

(a)
Temperature

Contour 1

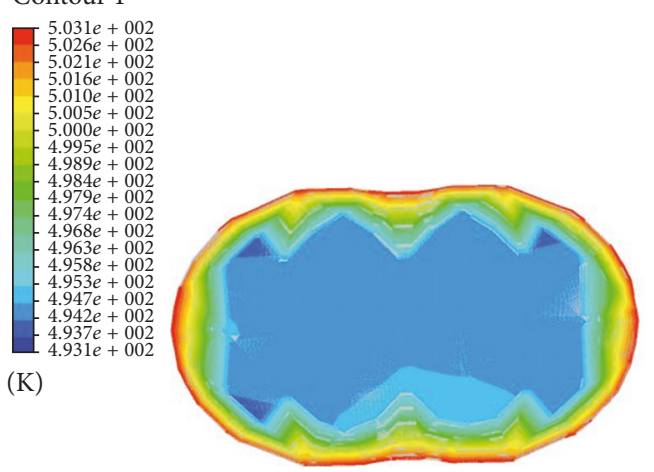

(b)

FiguRE 8: The temperature distribution in the steady state at the time of $50 \mathrm{~s}$ : (a) the temperature distribution of flow channel; (b) the temperature distribution of the cross section of the intersection.

3.3.4. Simulation Analysis of Two Inlets at a Velocity of $1 \mathrm{~mm} / \mathrm{s}$. The filament feed speed of both inlets is set to $1 \mathrm{~mm} / \mathrm{s}$ with the initial temperature set to $298.15 \mathrm{~K}$. There is a close contact between the heating block and the wall surface whose temperature is set to $508.15 \mathrm{~K}$. The process of filament material reaching intersection through branch pipe takes approximately $10 \mathrm{~s}$. The simulation time is set to $60 \mathrm{~s}$, in order to better observe the temperature distribution of ABS filament at the intersection. The temperature distribution of ABS filament in the flow channel at the time of $10 \mathrm{~s}$ is selected to represent the temperature changes, which are shown in Figure 10(a). The cross section of intersection is chosen to make temperature contours, which are shown in Figure 10(b).
It can be observed from Figure 10(a) that the filament material gathers at the intersection at the time of $10 \mathrm{~s}$. Neither the flow channel nor the ABS filament has reached the highest steady state temperature. The temperature of the cross section shown in Figure 10(b) is in zonal distribution as well. Meanwhile, the lowest temperature that is approximately $485 \mathrm{~K}$ equal to $212^{\circ} \mathrm{C}$ occurs in the center of the filament, which is lower than the temperature for smooth extrusion of filament. As a consequence, when the filament feed speed is increased to $1 \mathrm{~mm} / \mathrm{s}$, the molten filament at the intersection will not be available at the wall surface temperature of $508.15 \mathrm{~K}$.

The temperature of the wall surface rises to $513.15 \mathrm{~K}$ without any other changes in boundary conditions. As is shown 


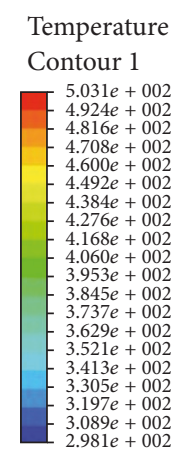

(K)
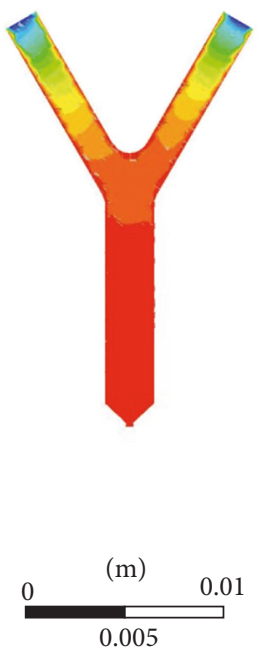

(a)
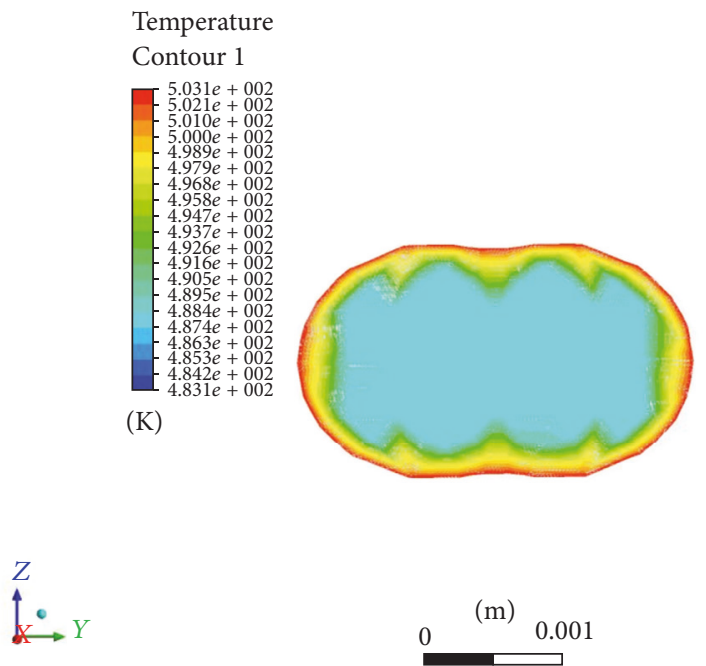

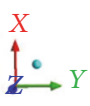

(b)

FIGURE 9: Temperature contours in the steady state at the temperature of $503.15 \mathrm{~K}$ at the time of $20 \mathrm{~s}$ : (a) temperature contours of the flow channel; (b) temperature contours of intersection cross section.

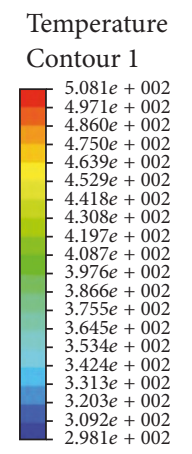

(K)

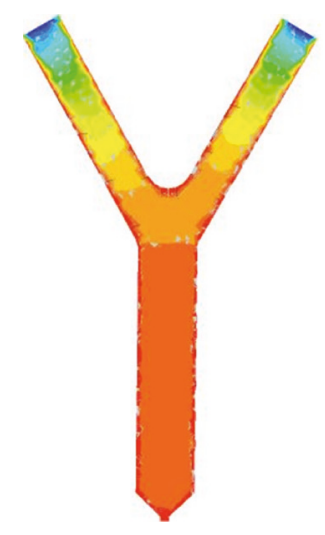

(a)

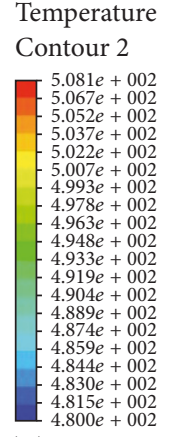

(K)

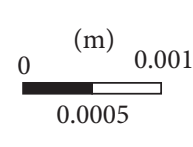

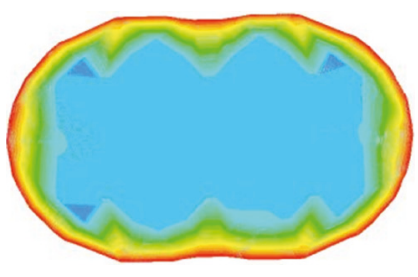

(b)

Figure 10: Temperature contours in the steady state at the temperature of $508.15 \mathrm{~K}$ at the time of $10 \mathrm{~s}$ : (a) temperature contours of the flow channel; (b) temperature contours of the intersection cross section.

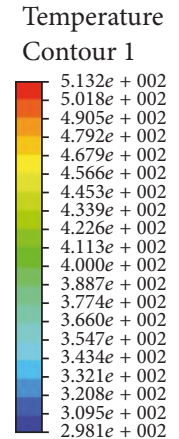

(K)

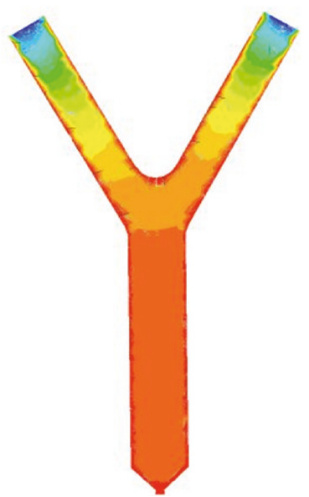

(a)

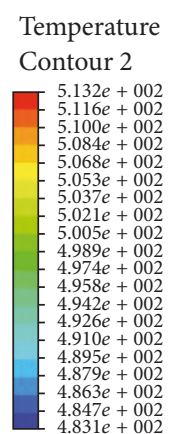

(K)

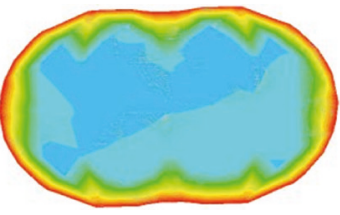

(b)

FIGURE 11: Temperature contours in the steady state at the temperature of $513.15 \mathrm{~K}$ at the time of $10 \mathrm{~s}$ : (a) temperature contours of the flow channel; (b) temperature contours of the intersection cross section. 


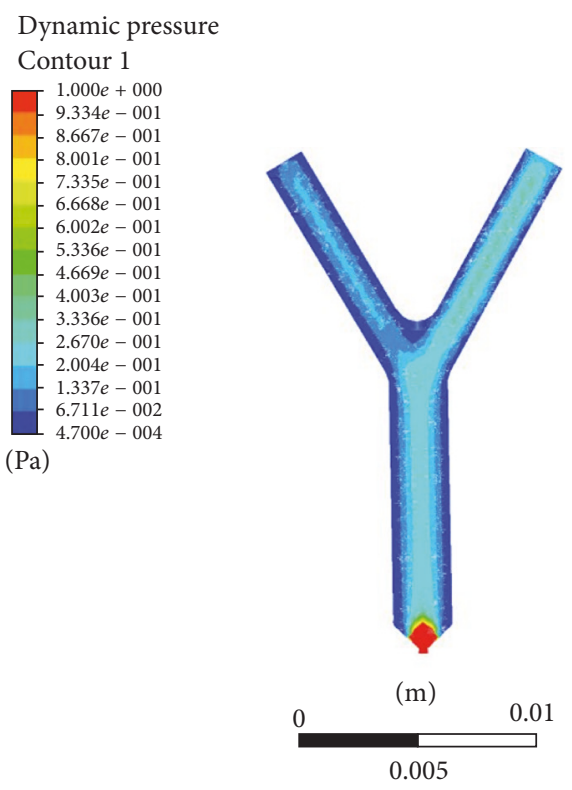

(a)

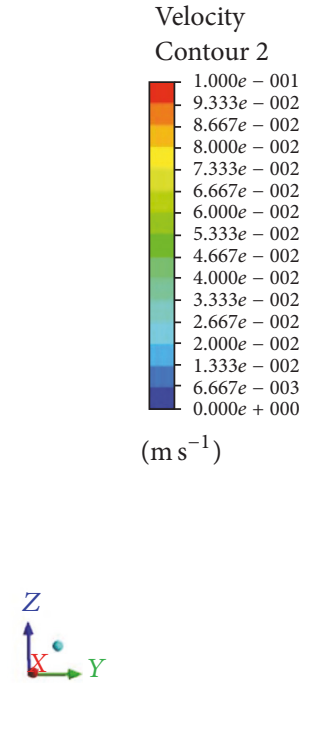

FIGURE 12: Pressure and velocity contours in the steady state: (a) pressure contours; (b) velocity contours. in Figure 11(a), the temperature distribution of the entire flow channel at a time of $10 \mathrm{~s}$ is extracted through simulation analysis. The cross section of intersection is chosen to make the temperature contours, which are as shown in Figure 11(b).

It can be seen from Figure 11(a) that the temperature distribution of channel is similar to that at the temperature of $508.15 \mathrm{~K}$. It can be seen from the temperature distribution of cross section in Figure 11(b) that the lowest temperature which occurs in the center of filament is approximately $489 \mathrm{~K}$ equal to $216^{\circ} \mathrm{C}$, which can meet the requirements for smooth extrusion of filament. However, the highest temperature of ABS filament will be approximately $513.15 \mathrm{~K}$, when the process is in a steady state. ABS filament will be decomposed at the temperature of $240^{\circ} \mathrm{C}$; meanwhile, the temperature of ABS filament will become higher faster by adding heat as soon as it enters into the flow channel, which will result in a premature softening of filament in the flow channel. As a consequence, molten filament material will not be extruded successfully.

Through the simulation analysis, it can be summed up that $1 \mathrm{~mm} / \mathrm{s}$ is too fast for the feed of filament to match the temperature field. During the test process, although the temperature field can meet the requirement for print, the speed of $1 \mathrm{~mm} / \mathrm{s}$ will lead to over speed of filament extrusion, as well as reduce the accuracy of print objects. In conclusion, a speed of $1 \mathrm{~mm} / \mathrm{s}$ is not appropriate for filament feed.

3.3.5. Simulation Analysis of Inlets at a Velocity of $0.2 \mathrm{~mm} / \mathrm{s}$ and $0.5 \mathrm{~mm} / \mathrm{s}$, Respectively. It can be known from the analysis that when the velocity of two inlets is $0.2 \mathrm{~mm} / \mathrm{s}$ and $0.5 \mathrm{~mm} / \mathrm{s}$, respectively, ABS filament at the intersection will be completely melted and mixed at the temperature of $503.15 \mathrm{~K}$. In order to further study the feasibility of the device, the finite element model is imported into Fluent software. The speed of the first inlet is set to $0.2 \mathrm{~mm} / \mathrm{s}$ with the speed of the second inlet being set to $0.5 \mathrm{~mm} / \mathrm{s}$. The initial temperature is set to $298.15 \mathrm{~K}$. There is close contact between the heating block and the wall surface whose temperature is set to $503.15 \mathrm{~K}$. The simulation time is set to $60 \mathrm{~s}$, and the ABS filament reaches a steady state after $50 \mathrm{~s}$. The distribution of velocity field, pressure field, and temperature field of ABS filament existing in the flow channel at the time of $50 \mathrm{~s}$ is observed.

The pressure field and velocity field distribution of ABS filament existing in the flow channel in a steady state at the time of $50 \mathrm{~s}$ can be obtained through this simulation. The pressure contours of ABS filament existing in the flow channel in the steady state are shown in Figure 12(a). It can be observed from Figure 12(a) that the flow channel is under high pressure because of high inlet velocity. The pressure of molten ABS filament at a speed of $0.5 \mathrm{~mm} / \mathrm{s}$ is evidently higher than that of $0.2 \mathrm{~mm} / \mathrm{s}$. As a consequence, part of molten ABS filament under high pressure will move to an area of less pressure, which will cause a partial reflux. Also, the normal fluid under low pressure is restricted by the fluid under high pressure. It can be seen from the velocity contours in Figure 12(b) that the flow speed near the wall of the pipe is low, and, on the contrary, the flow speed near the center of the pipe is high, because great friction occurs between the molten filament material and the pipe wall surface. In a real world situation, a Teflon hollow tube that will be added to the inner wall of the pipe is composed of polytetrafluoroethylene. The material has a low coefficient of friction, remains stable at elevated temperatures, and offers good resistance to close connection between ABS filament and the inner wall of the device. In that case, the flow speed of the molten material in the pipeline will be increased.

In order to realize the function of color mixing print better, the cross sections of pressure contours, velocity contours, 


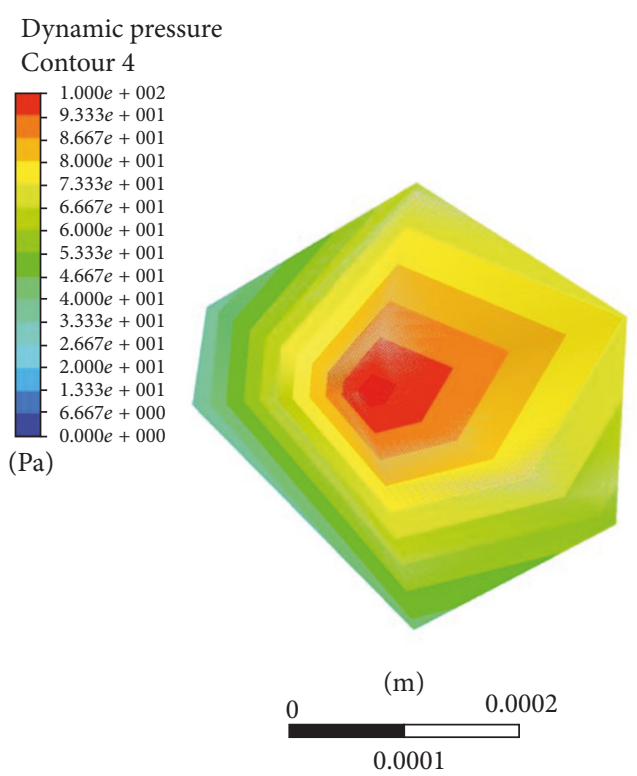

(a)

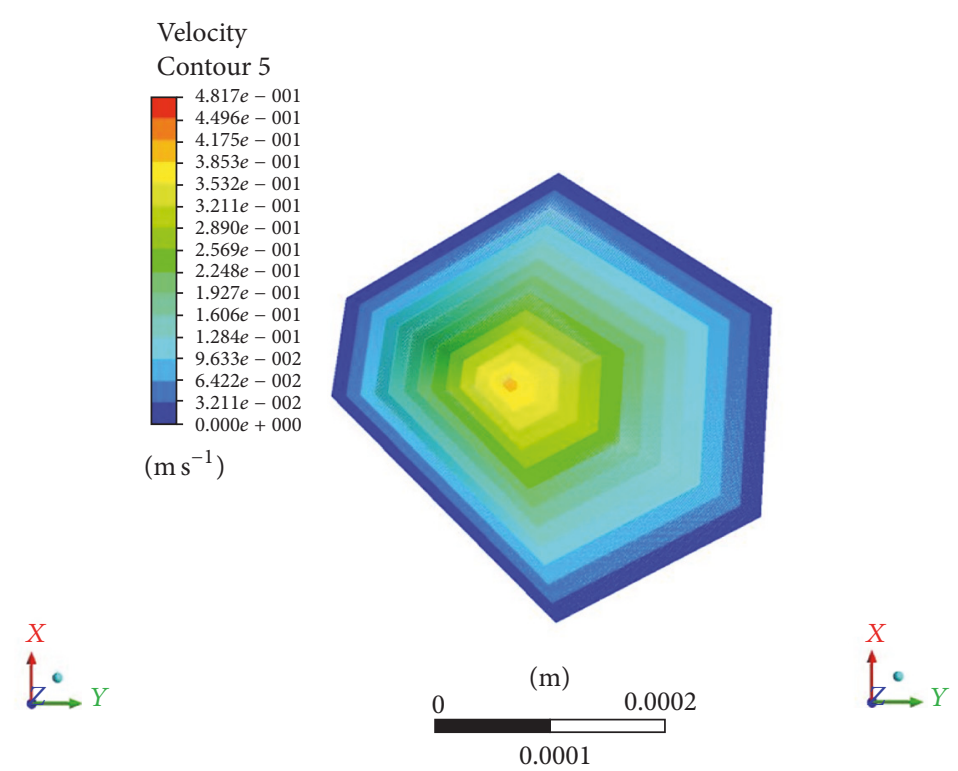

(b)

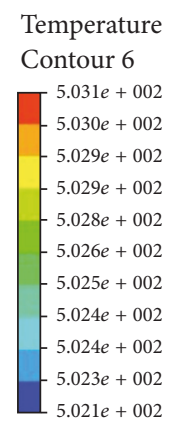

(K)

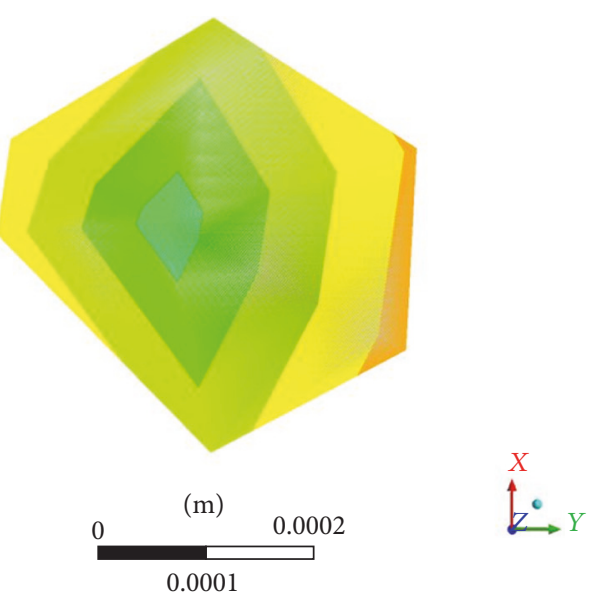

(c)

FIGURE 13: Contours of cross section at nozzle: (a) pressure contours; (b) velocity contours; (c) temperature contours.

and temperature contours are presented in Figure 13. It can be seen from the pressure contours that there is a polygonal area with a lower pressure in the center as compared to the surrounding region while the pressure distribution is basically uniform. It can be seen from the velocity contours that there is an area with a higher speed in the center as compared to the surrounding region while the distribution of speed is basically uniform. It can be concluded that the velocity distribution in the nozzle hole area will not be affected by the velocity of the two-inlet area that only determines the peak velocity in the nozzle hole. It can be seen from the temperature contours that although cross section temperature field distribution in outlet area is zonal, the temperature gradient is small; meanwhile, the temperature difference between center area and boundary area is less than $1 \mathrm{~K}$. It can be concluded that the filament reaching nozzle hole has been heated to be completely melted, so the possibility of blockage occurring in nozzle hole area can be ignored.

\section{Test Verification and Structure Improvement of the Nozzle for Color Mixing Device}

4.1. Test Verification of the Nozzle for Color Mixing Device. Based on the simulation of flow for the whole device, the test of the whole device is carried out to verify whether it can meet the requirements for color mixing print. The heating 


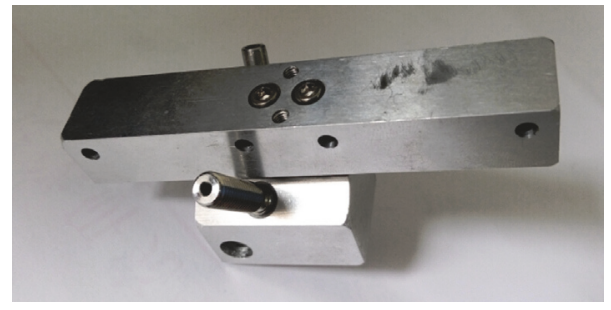

FIGURE 14: 3D printer device for color mixing.

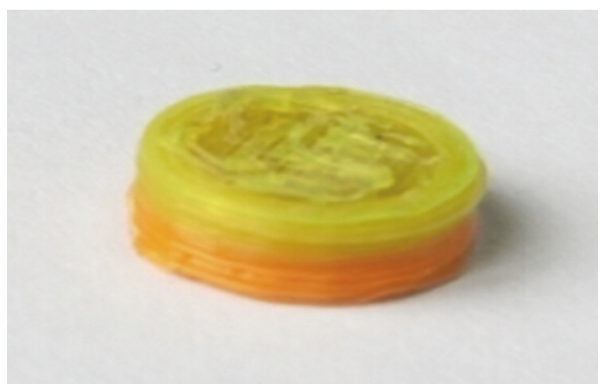

(a)

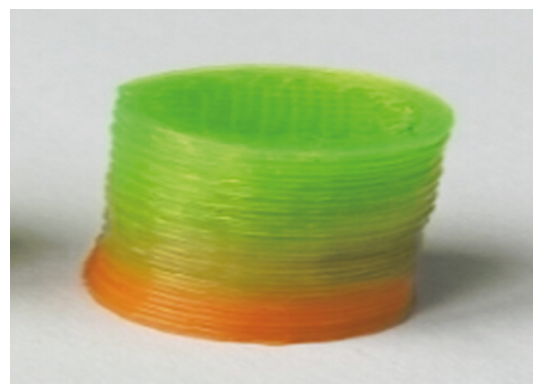

(b)

FIgURE 15: 3D printing objects at the temperature of $220^{\circ} \mathrm{C}$ : (a) blocked; (b) successful.

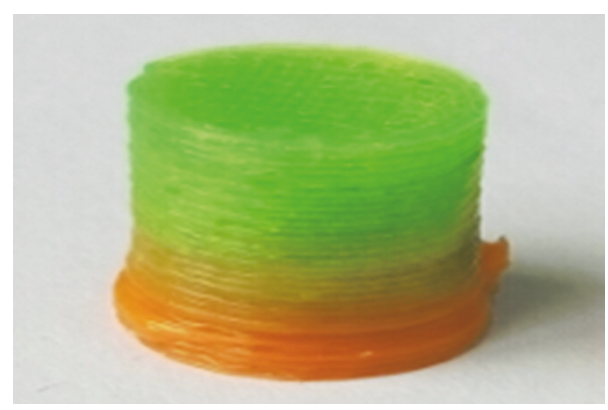

Figure 16: 3D printing object at the temperature of $230^{\circ} \mathrm{C}$.

block and the fixed block are produced in terms of design parameters. The parts of the heating block and fixed block are then assembled immediately and clamped together. The assembled color mixing head is shown in Figure 14.

The whole mixing head is fixed on the 3D printer, and the heating pipe and the thermal resistor are arranged on the heating block. The 3D printer connects to a computer via a USB cable running Repetier-Host software that controls the heating block [26-28]. The temperature of the heating block is set in terms of the melting point of filament. When the temperature reaches the set temperature, the filament can be fed into the heating block along the throat pipe. Two kinds of filament will be melted at the end of the pipe and mix in the heating block. With the continuous supplies of material, mix melt will be extruded through the nozzle. Different mixing effects will be realized through controlling the speed of the stepper motor. The test is mainly to verify the feasibility of the device at a temperature of $220^{\circ} \mathrm{C}$ and $230^{\circ} \mathrm{C}$, respectively. Orange and green ABS filaments are chosen to be tested. Meanwhile, a cylinder whose diameter and height are $10 \mathrm{~mm}$ and $10 \mathrm{~mm}$, respectively, is regarded as a printing model. The color mixing nozzle is a mechanical device with dual inlets and a unique outlet. The cylinder model is sliced by RepetierHost software. In order to meet the requirements for mixing color print, part of the codes is modified in terms of the color mixing requirements.

For the first time, the temperature of the nozzle is set to $220^{\circ} \mathrm{C}$ to print objects. During the initial test, when onethird of the model is finished, as can be seen in Figure 15(a), the extrusion stops, and the filament slips under continuous supply. The nozzle device is disassembled after cooling. Blockage occurs at the intersection of the end of pipe and heating block. Secondly, the test of the whole nozzle device at the temperature of $220^{\circ} \mathrm{C}$ is carried out after the whole nozzle device is cleaned up, as can be seen in Figure 15(b); the outcome of a mix of colors is obvious without evident phenomenon of stratification and accumulation. After the nozzle device is cleaned up, the temperature of the nozzle is set to $230^{\circ} \mathrm{C}$ for forming; as a result, the print test is a success. The test results are as shown in Figure 16.

It can be seen from the outcome of the color mixing test that the filament at the intersection of the nozzle is not completely melted at the temperature of $220^{\circ} \mathrm{C}$. When the feed of filament is not smooth or steady, the nozzle is at a great risk of being blocked by ABS material. The filament can be smoothly mixed at the nozzle temperature of $230^{\circ} \mathrm{C}$; however, the phenomenon of molten filament accumulation can be seen clearly, which will harm the forming effects. It 
shows that molten ABS material existing in the nozzle has a low stickiness and a strong liquidity at a temperature of $230^{\circ} \mathrm{C}$, which results in an incomplete extrusion of ABS material.

The outcome of the test shows that the mixing nozzle device can realize the function of mixing print basically. By analyzing the outcome of the test, it can be found that there exists a risk that blockage may occur in the intersection of the heating block. Meanwhile, it can be seen from the outcome of the test that a flaw exists in the design of the intersection. In order to remove the risk of blockage existing in the device, the structure of the device needs improvement in the future.

\section{Conclusions}

As a kind of mature rapid prototyping technology, fused deposition modeling has been a new production method in the 21st century. In this paper, the CAD model of $3 \mathrm{D}$ printer color mixing nozzle device is established by UG software; meanwhile, the flow channel part of the whole device is extracted and simplified. The CAD model and the finite element model are established by UG and ICEM CFD, respectively, and then the flow field is simulated by Fluent software. Combined with the simulation results, the test print of the color mixing nozzle device is performed. According to the test, the structure of 3D printer nozzle is improved. After the above research, the conclusions are as follows.

(1) The flow field of the simplified flow channel of the mixing nozzle device is simulated by using the Fluent software. The results are as follows: The flow condition of the filament is complex, and the control of the temperature field is the key factor in mixing color print. The suitable temperature of the nozzle at different extrusion speeds is obtained, and the reason for the blockage of filament material at the intersection of the heating block is revealed.

(2) The feasibility and practicability of the device are verified through the test, but the defect of the whole device is also found through the test results. In order to remove the risk of blockage existing in the device, the improved structure of the device is needed in the future.

\section{Conflicts of Interest}

The authors declare that they have no conflicts of interest.

\section{Acknowledgments}

This work was financially supported by the National Natural Science Foundation of China under Grant no. 51375282, the Important Science \& Technology Specific Projects of Shandong Province under Grant no. 2015ZDXX0601C01, a Project of Shandong Province Higher Educational Science and Technology Program under Grant no. J17KA018, and the Science \& Technology Innovation Fund for Graduate Students of Shandong University of Science and Technology under Grant no. SDKDYC170242.

\section{References}

[1] A. Garland and G. Fadel, "Design and manufacturing functionally gradient material objects with an off the shelf threedimensional printer: challenges and solutions," Journal of Mechanical Design, vol. 137, no. 11, 11 pages, 2015.

[2] P. J. Goodrich, F. Sharifi, and N. Hashemi, "Rapid prototyping of microchannels with surface patterns for fabrication of polymer fibers," RSC Advances, vol. 5, no. 87, pp. 71203-71209, 2015.

[3] Z. H. Yu, H. M. Wang, and G. X. Chen, "Effects of nozzle distance on micro quality in 3D printing," Applied Mechanics and Materials, vol. 644-650, pp. 4900-4904, 2014.

[4] J. Hergel and S. Lefebvre, "Clean color: improving multifilament 3D prints," Computer Graphics Forum, vol. 33, no. 2, pp. 469-478, 2014.

[5] L. Galantucci, I. Bodi, J. Kacani, and F. Lavecchia, "Analysis of dimensional performance for a 3D open-source printer based on fused deposition modeling technique," Procedia CIRP, vol. 28, pp. 82-87, 2015.

[6] L. Ciocca, C. Marchetti, S. Mazzoni et al., "Accuracy of fibular sectioning and insertion into a rapid-prototyped bone plate, for mandibular reconstruction using CAD-CAM technology," Journal of Cranio-Maxillofacial Surgery, vol. 43, no. 1, pp. 28-33, 2015.

[7] K. Namba, A. Higaki, N. Kaneko, T. Mashiko, S. Nemoto, and E. Watanabe, "Microcatheter shaping for intracranial aneurysm coiling using the 3-dimensional printing rapid prototyping technology: preliminary result in the first 10 consecutive cases," World Neurosurgery, vol. 84, no. 1, pp. 178-186, 2015.

[8] J. Domanski, K. Skalski, R. Grygoruk, and A. Mróz, "Rapid prototyping in the intervertebral implant design process," Rapid Prototyping Journal, vol. 21, no. 6, pp. 735-746, 2015.

[9] E. A. Nasr, A. M. Al-Ahmari, H. Alkhawashki, A. Altamimi, and M. Alkhuraisi, "Developing a methodology for analysis and manufacturing of proximal interphalangeal (PIP) joint using rapid prototyping technique," Rapid Prototyping Journal, vol. 21, no. 4, pp. 449-460, 2015.

[10] A. D. Lantada, V. Piotter, K. Plewa, N. Barié, M. Guttmann, and M. Wissmann, "Toward mass production of microtextured microdevices: linking rapid prototyping with microinjection molding," International Journal of Advanced Manufacturing Technology, vol. 76, no. 5-8, pp. 1011-1020, 2015.

[11] A. Klodowski, H. Eskelinen, and S. Semken, "Leakage-proof nozzle design for RepRap community 3D printer," Robotica, vol. 33, no. 4, pp. 721-746, 2015.

[12] R. Pastirčák, A. Sládek, and E. Kucharčíková, “The production of plaster molds with patternless process technology," Archives of Foundry Engineering, vol. 15, no. 2, pp. 91-94, 2015.

[13] M. Zhang, A. Vora, W. Han et al., "Dual-responsive hydrogels for direct-write 3D printing," Macromolecules, vol. 48, no. 18, pp. 6482-6488, 2015.

[14] T. Reiner, N. Carr, R. Měch, O. Št’Ava, C. Dachsbacher, and G. Miller, "Dual-color mixing for fused deposition modeling printers," Computer Graphics Forum, vol. 33, no. 2, pp. 479-486, 2014.

[15] C. A. Arikan, A. Brunton, T. M. Tanksale, and P. Urban, "Color-managed 3D-printing with highly translucent printing materials," in Measuring, Modeling, and Reproducing Material Appearance 2015, 2015.

[16] S. Khalil, J. Nam, and W. Sun, "Multi-nozzle deposition for construction of 3D biopolymer tissue scaffolds," Rapid Prototyping Journal, vol. 11, no. 1, pp. 9-17, 2005. 
[17] Z. Weng, J. Wang, T. Senthil, and L. Wu, "Mechanical and thermal properties of ABS/montmorillonite nanocomposites for fused deposition modeling 3D printing," Materials \& Design, vol. 102, pp. 276-283, 2016.

[18] F. Lederle, F. Meyer, G. Brunotte, C. Kaldun, and E. G. Hübner, "Improved mechanical properties of 3D-printed parts by fused deposition modeling processed under the exclusion of oxygen," Progress in Additive Manufacturing, vol. 1, no. 1-2, pp. 3-7, 2016.

[19] A. Kantaros, N. Chatzidai, and D. Karalekas, "3D printingassisted design of scaffold structures," International Journal of Advanced Manufacturing Technology, vol. 82, no. 1-4, pp. 559571, 2016.

[20] K. T. Lee, E.-S. Kim, W.-S. Chu, and S.-H. Ahn, "Design and $3 \mathrm{D}$ printing of controllable-pitch archimedean screw for picohydropower generation," Journal of Mechanical Science and Technology, vol. 29, no. 11, pp. 4851-4857, 2015.

[21] V. Ken, “3D printers: judgment day," Industrial Laser Solutions, vol. 28, no. 2, pp. 12-15, 2013.

[22] F. Acuna, D. Rivas, S. Chancusi, and P. Navarrete, "Design and construction of a $3 \mathrm{D}$ printer auto controller wirelessly through of free software," IEEE Latin America Transactions, vol. 13, no. 6, pp. 1893-1898, 2015.

[23] X. Song, Y. Pan, and Y. Chen, "Development of a low-cost parallel kinematic machine for multidirectional additive manufacturing," Journal of Manufacturing Science and Engineering, Transactions of the ASME, vol. 137, no. 2, Article ID 021005, 2015.

[24] M. Dawoud, I. Taha, and S. J. Ebeid, "Mechanical behaviour of ABS: an experimental study using FDM and injection moulding techniques," Journal of Manufacturing Processes, vol. 21, pp. 3945, 2016.

[25] P. Dudek, "FDM 3D printing technology in manufacturing composite elements," Archives of Metallurgy and Materials, vol. 58, no. 4, pp. 1415-1418, 2013.

[26] K. Kun, "Reconstruction and development of a 3D printer using FDM technology," Procedia Engineering, vol. 149, pp. 203-211, 2016.

[27] R. Singh, S. Singh, and K. Mankotia, "Development of ABS based wire as feedstock filament of FDM for industrial applications," Rapid Prototyping Journal, vol. 22, no. 2, pp. 300-310, 2016.

[28] K. Szykiedans and W. Credo, "Mechanical properties of FDM and SLA low-cost 3-D prints," Procedia Engineering, vol. 136, pp. 257-262, 2016. 

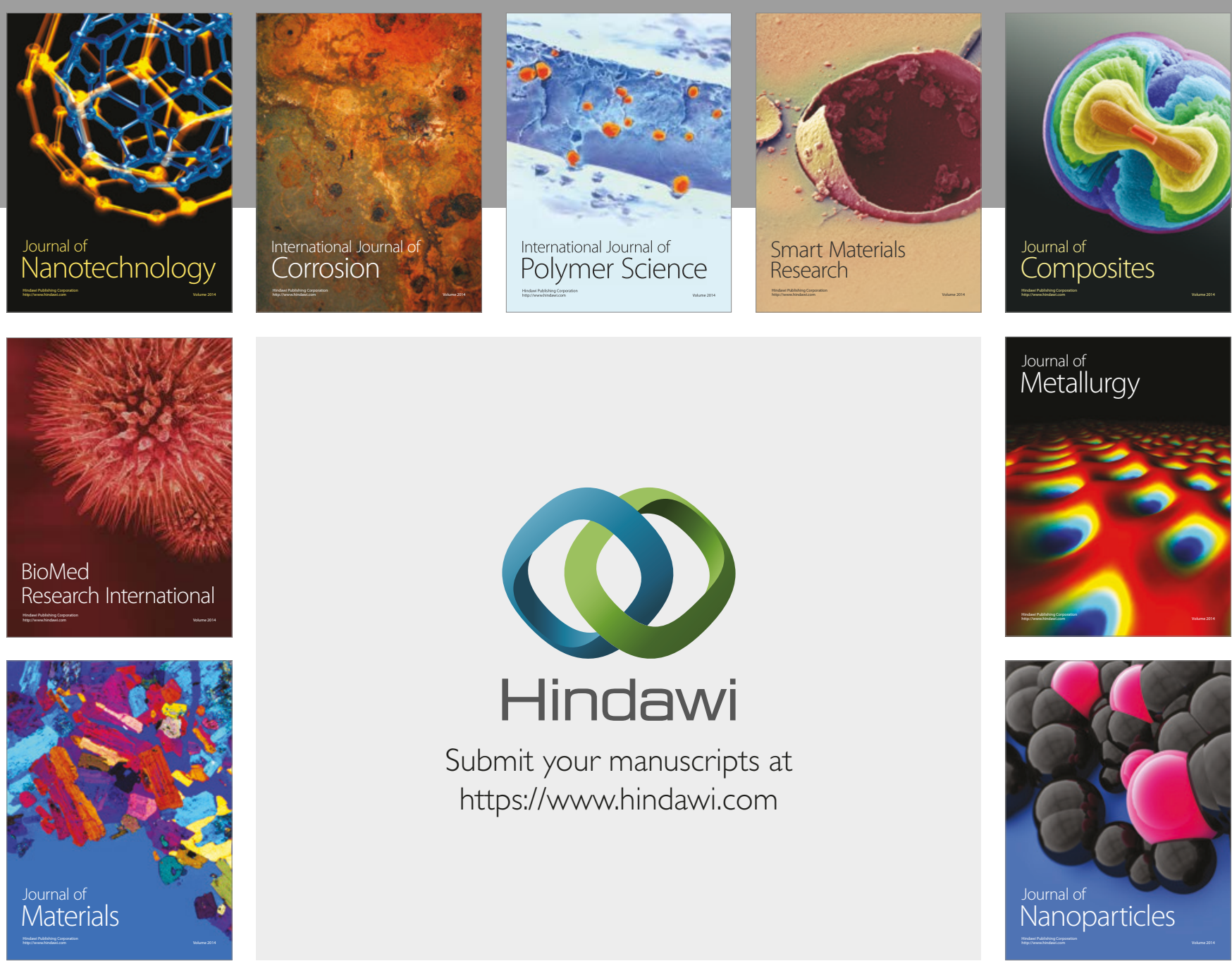

\section{Hindawi}

Submit your manuscripts at

https://www.hindawi.com
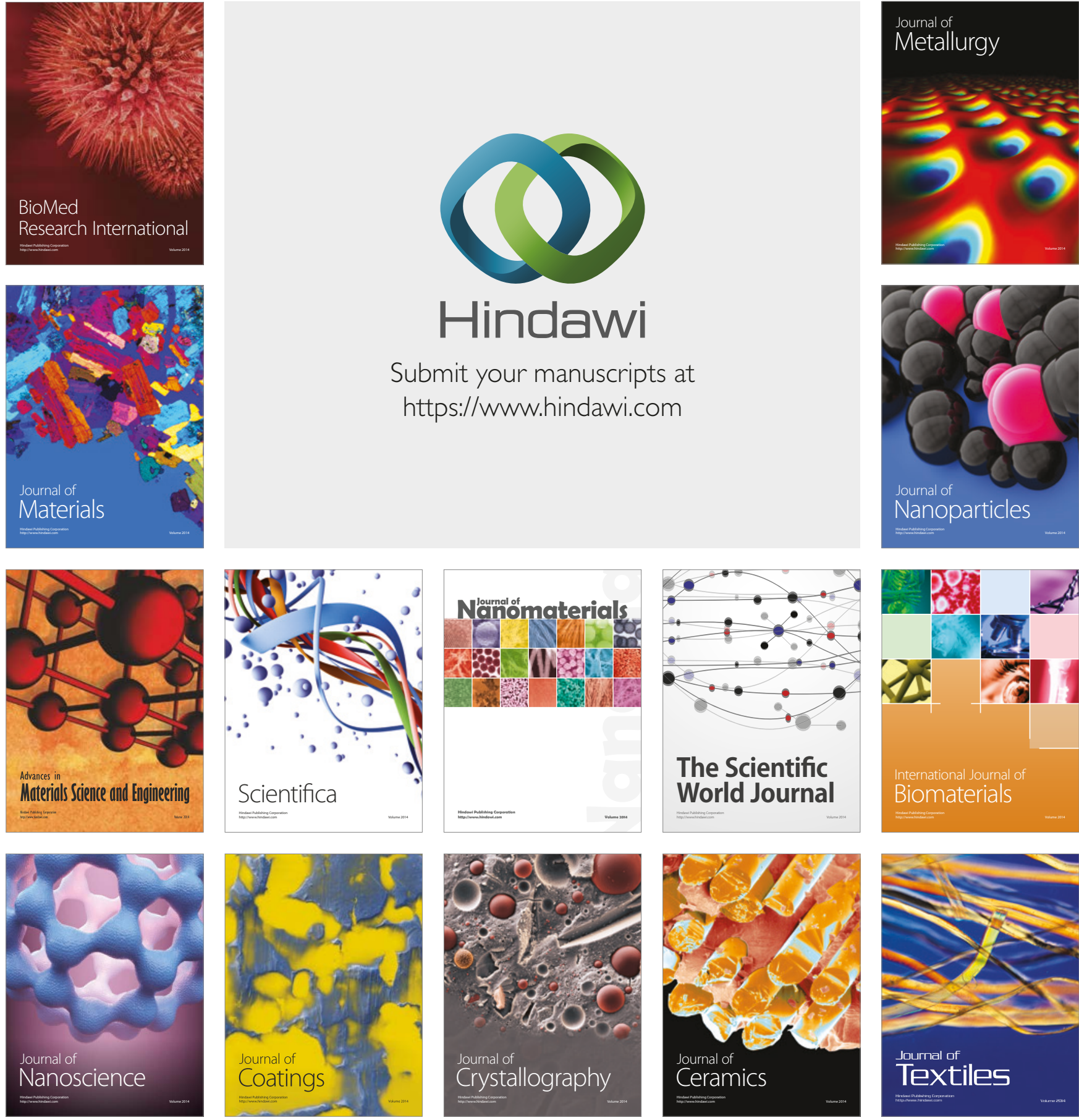

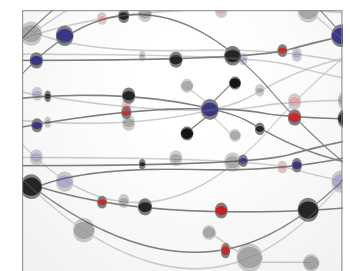

The Scientific World Journal
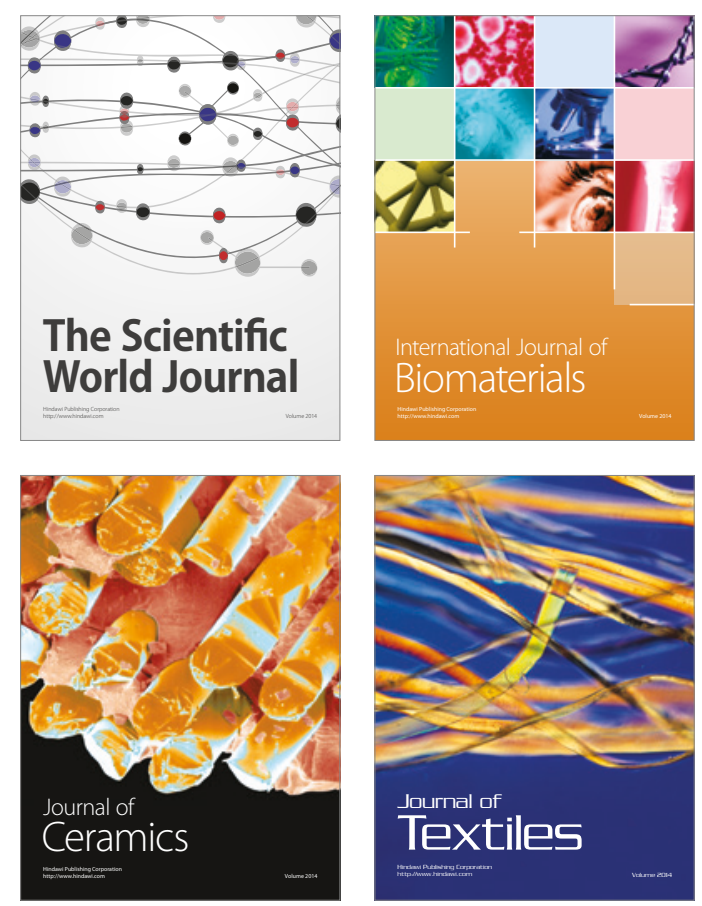